\title{
AVALIAÇÃO DO DISCO INTERVERTEBRAL DE RATOS WISTAR APÓS USO DE EXPERIMENTAL SUIT THERAPY
}

\begin{abstract}
Thiago Fernando Mattjie*, Camila Thieime Rosa*, Márcia Cristina Dias Borges*, Rose Meire Costa Brancalhão*, Lucinéia de Fátima Chasko Ribeiro*, Gladson Ricardo Flor Bertolini*
\end{abstract}

Autor correspondente: Gladson Ricardo Flor Bertolini. E-mail: gladsonricardo@gmail.com

* Universidade Estadual do Oeste do Paraná (Unioeste).

\section{Resumo}

Objetivos: visto que a sobrecarga ou pressão inadequada sobre as estruturas do disco intervertebral podem causar degeneração discal, este estudo teve como objetivo, avaliar um modelo experimental da suit therapy sobre os discos intervertebrais do segmento torácico da coluna, avaliando a altura na sua porção anterior, medial e posterior, como também da altura do núcleo pulposo. Métodos: 30 ratos Wistar, foram separados em 5 grupos ( $G_{1}$ - controle; $G_{2}$ - simulação do uso da suit; $G_{3}-2$ horas com a suit; $\mathrm{G}_{4}-2$ horas com peso adaptado; $\mathrm{G}_{5}-2$ horas com a vestimenta e bandas de tração). Foi confeccionado um modelo experimental da vestimenta, tipo macacão terapêutico. $O$ experimento teve duração de 4 semanas, com a colocação da vestimenta em 5 dias consecutivos, com pausa de 2 dias. Ao final o segmento torácico da coluna vertebral foi dissecado na região do cruzamento das bandas elásticas, entre T7 e T10. Os segmentos foram fixados em formol, clivados longitudinalmente, no plano mediano, tendo como base os processos espinhosos, seccionados em espessura de $7 \mu \mathrm{m}$, e corados em Hematoxilina-Eosina (HE). As imagens foram obtidas por fotomicrografia e analisadas as alturas nas regiões anterior, média e posterior do disco, e ainda, a altura do núcleo pulposo. Resultados: não houve diferença significativa, na mensuração das alturas avaliadas. Conclusão: Conforme o protocolo, de compressão do disco, apresentado não houve alterações morfométricas do disco intervertebral torácico de ratos Wistar.

Palavras chave: Fisioterapia; Coluna vertebral; Degeneração do disco intervertebral. 


\title{
INTERVERTEBRAL DISC EVALUATION OF WISTAR RATS AFTER SUIT THERAPY EXPERIMENTAL
}

\begin{abstract}
Objectives: Since overloading or improper pressure on the intervertebral disk structures can cause disc degeneration, this study aimed to evaluate an experimental model of suit therapy on the intervertebral discs of the thoracic segment of the column, evaluating the height at the anterior, medial and posterior portions, as well as the height of the nucleus pulposus. Methods: 30 Wistar rats were divided into 5 groups $\left(\mathrm{G}_{1}-\right.$ control; $G_{2}$ - simulating the use of the suit; $G_{3}-2$ hours with a suit; $G_{4}-2$ hours with adjusted weight; $G_{5}$ -2 hours with the dress and elastic bands). An experimental model of suit, type therapeutic jumpsuit was made. The experiment lasted 4 weeks, putting the garment on 5 consecutive days, with a break of two days. At the end of the thoracic spinal segment was dissected in the region of the intersection of elastic bands, between $\mathrm{T}_{7}$ and $\mathrm{T}_{10}$. The segments were fixed in formalin, cleaved along, in the median region, based on the spinous processes, cut into thick $7 \mu \mathrm{m}$, and stained with hematoxylin-eosin (HE). Images were obtained and analyzed by photomicrography heights in the anterior, middle and posterior disc, and also the height of the nucleus pulposus. Results: there was no significant difference in the measurement of the evaluated heights. Conclusion: in the protocol compression disc provided there were no morphological changes of the thoracic intervertebral disc Wistar rats.
\end{abstract}

Keywords: Physical therapy specialty; Spine; Intervertebral disc degeneration.

\section{INTRODUÇÃO}

O disco intervertebral é uma estrutura localizada entre duas vértebras, que tem como funções manter a ligação e permitir a movimentação entre elas, além de absorver impacto. É organizado em três estruturas: o núcleo pulposo, que é um centro gelatinoso, rico em proteoglicanos, com função de absorção da pressão exercida sobre o disco e retenção da água no interior do disco; o anulo fibroso, que é a estrutura mais externa, é rica em colágeno e se organiza em fitas concêntricas que confina o núcleo no centro do disco; e a placa terminal, que são placas de cartilagens hialina localizadas entre o anulo fibroso e os corpos vertebrais, que servem de interface entre a vértebra e o disco, e auxiliam na nutrição. As três estruturas são ricas em con- drócitos e proteoglicanos, que têm como função manter um gradiente negativo dentro do disco, criando uma diferença de pressão, para retenção de água em seu interior. ${ }^{(1-3)}$ Todas essas estruturas tem a mesma origem embrionária, que são células oriundas da notocorda, que tem a tendência de ser substituído por células similares aos condrócitos. (2-6).

A degeneração do disco intervertebral é um processo patológico degenerativo. Resulta de alterações mecânicas, levando à desidratação do núcleo, diminuição dos proteoglicanos e do colágeno, desorganização e ruptura das lâminas do anulo fibroso e mudança fenotípica das células do tecido discal. São vários os fatores que favorecem a de- 
generação discal como: genéticos, hábitos de vida (obesidade e atividade laboral), infecções e sobrecarga biomecânica inadequada. Tais fatores vão gradualmente enfraquecendo as estruturas do disco intervertebral levando a respostas moleculares inadequadas, que prejudicam a regeneração das células e levam à uma perda da quantidade de água no interior do disco intervertebral. ${ }^{(3,6,7)} \mathrm{O}$ início dessa degeneração discal determina uma produção anormal de moléculas pró-inflamatórias, desencadeando uma resposta inadequada do sistema imunológico levando a autofagia e apoptose das células. ${ }^{(7)} A$ degeneração é um dos fatores que levam ao surgimento da dor sobre algum segmento da coluna lombar que acarreta em sérios distúrbios sobre a qualidade de vida dos indivíduos, ${ }^{(8)}$ além de um grande problema de saúde pública, pelos altos custos para o tratamento e o afastamento de indivíduos economicamente produtivos do trabaIho. ${ }^{(9)}$

Quando cargas compressivas são aplicadas sobre os discos intervertebrais o estresse acumulase sobre o núcleo pulposo e apenas uma pequena parte do estresse sobre o ânulo fibroso. A compressão causa um aumento gradual e de forma igual em toda a parte interna do núcleo, transformando parcialmente as forças verticais em horizontais; estas causam uma deformação radial do ânulo fibroso. Assim, os discos intervertebrais possuem a capacidade de se deformar viscoelasticamente ao serem submetidos a cargas compressivas, causando uma redução na sua altura. Tal redução causa diminuição no comprimento da coluna vertebral e podem ser utilizadas como índice de estresse sobre a mesma. ${ }^{(10)}$ A redução na altura dos discos intervertebrais ocorre de forma exponencial, sendo verificada uma grande perda no ciclo de cargas de compressão, alteração elástica, associada com uma gradativa e lenta perda na altura dos discos e uma deformação viscosa. ${ }^{(9)}$ Constantes cargas mecânicas, com o aumento da idade, apresentam uma importante contribuição para o início destas alterações metabólicas nos elementos da matriz dos discos. ${ }^{(10)}$
A falta de carga sobre a coluna, também é maléfica para os discos intervertebrais. Animais que foram lançados experimentalmente para o espaço, retornaram com avançado grau de degeneração do disco intervertebral por meio da desidratação do seu interior. ${ }^{(10)}$ Para amenizar essa degeneração foi desenvolvido pelo antigo programa espacial soviético, da década de 70, um traje que exercia uma sobrecarga sobre as articulações, fazendo uso de um sistema de correias para aplicar essa pressão sobre o sistema musculoesquelético, com finalidade de amenizar os efeitos maléficos da ausência de gravidade. Atualmente esse tipo de vestimenta foi adaptado e vem sendo muito utilizado com finalidade terapêutica, em programas de tratamento intensivo, visando proporcionar carga sobre o sistema musculoesquelético, melhorar o posicionamento corporal, favorecer o ganho funcional e reduzir déficits motores, principalmente nos tratamentos fisioterapêuticos de pacientes neurológicos. As sessões desse programa intensivo são realizadas de 3 a 6 horas diárias com frequência de 5 a 6 vezes por semana, por cerca de 3 a 4 semanas, variando de acordo com o protocolo utilizado, AdeliMethod, TheraSuitMethod, PediaSuitMethod ou NeuroSuitMethod. Estes programas baseiam-se em três princípios: efeito da roupa; treino fisioterapêutico intensivo em habilidades motoras; participação motora ativa do paciente. ${ }^{(1,12)} \mathrm{O}$ programa intensivo se mostra um recurso promissor no tratamento de pacientes neurológicos, mas ainda necessita de estudos, para comprovar se o traje produz ou não, benefícios para os indivíduos que utilizam essa vestimenta como também a sua ação sobre o sistema musculoesquelético. ${ }^{(13)}$

Sendo a sobrecarga de peso ou pressão inadequada sobre as estruturas do disco intervertebral, a maior causa de degeneração das estruturas e lesão, este estudo teve como objetivo, avaliar a interferência de um modelo experimental, tipo suit therapy, com elásticos sobre as modificações das estruturas dos discos intervertebrais do segmento torácico da coluna, avaliando a altura na sua porção anterior, medial e posterior, como também da altura do núcleo pulposo. 


\section{MATERIAIS E MÉTODOS}

Trata-se de uma pesquisa experimental, aprovada pelo Comitê de Ética em Uso de Animais da Universidade Estadual do Oeste do Paraná (Unioeste) em 11/04/2014, transversal, de dimensão quantitativa, com amostra composta por 30 ratos Wistar machos, com aproximadamente 8 semanas de idade, massa média de $360,90 \pm 26,26 \mathrm{~g}$. Os animais foram obtidos no biotério central da Universidade Estadual do Oeste do Paraná, campus Cascavel, mantidos em caixas de polipropileno, sem restrições para a alimentação e água, temperatura controlada $\left(24^{\circ} \mathrm{C} \pm 1^{\circ} \mathrm{C}\right)$ e ciclo claro/escuro de 12 horas.

Foi confeccionado um modelo experimental da vestimenta, tipo macacão terapêutico, apresentado por Borges et al. (14). Esta vestimenta foi composta por uma parte superior e uma inferior, fechadas com velcros. Elaborada com tecido de algodão cru, 180 fios, na qual foram adaptados dois elásticos dispostos em " $X$ ", para a aproximação vertebral do segmento torácico por meio de tração, com carga de $50 \%$ do peso do animal.

O cálculo da carga da tensão elástica foi realizado por meio de deslocamento dos elásticos, que foram analisados na célula de carga de escala 100kgf, SB-100 da LYNX (sensibilidade 1,4622 mV/V e alimentação $12 \mathrm{~V} \mathrm{cc}$ ).

A amostra foi dividida aleatoriamente em 5 grupos ( $G_{1}$ a $\left.G_{5}\right)$, com 6 animais em cada grupo:

- G1-Grupo controle;

- $\mathrm{G}_{2}$ - Grupo que usou a vestimenta e retirada da mesma em seguida;

- $\mathrm{G}_{3}$ - Permanência de 2 horas somente com a vestimenta;

- $\mathrm{G}_{4}$ - Permanência de 2 horas diárias com peso adaptado na vestimenta;

- $G_{5}$ - Permanência de 2 horas diárias com a vestimenta e bandas de tração.

Para $\mathrm{G}_{4}$ e $\mathrm{G}_{5}$, foi fornecida carga de aproximadamente $50 \%$ do peso corporal do animal. $\mathrm{Em} \mathrm{G}_{5}$ a tração por meio de 2 elásticos tracionados e dispostos em " $X$ " sobre o dorso do animal $( \pm 25 \%$ de carga em cada elástico), e para $\mathrm{G}_{4}$ a carga foi fornecida por meio de pesos acoplados lateralmente à vestimenta ( $\pm 25 \%$ de carga em cada peso). Para tanto, os animais foram previamente pesados antes do início de cada semana, para reajuste da carga. O deslocamento dos elásticos foi medido com paquímetro digital da marca Digimess $($ ) (São Paulo/ Brasil). $\mathrm{G}_{3}$ permaneceu com a vestimenta durante o mesmo período de $\mathrm{G}_{4}$ e $\mathrm{G}_{5}$, porém sem nenhuma adição de peso ou tração por elásticos, o tempo de permanência com a vestimenta, foi de duas horas, sendo os animais mantidos dentro das caixas de polipropileno durante esse período, e o $\mathrm{G}_{2}$ foi um grupo controle que sofreu apenas o estresse da colocação e retirada da vestimenta que os demais grupos ( $G_{1}, G_{2}$ e $\left.G_{3}\right)$, sendo assim, igualados no que diz respeito à manipulação experimental.

O experimento teve duração de 4 semanas, com a colocação da vestimenta em 5 dias consecutivos, com pausa de 2 dias. No dia seguinte ao último dia de experimento, os animais foram pesados, totalizando $388,26 \pm 35,66 \mathrm{~g}$, e anestesiados com cloridrato de quetamina $(50 \mathrm{mg} / \mathrm{kg}$ ) e cloridrato de xilazina (10mg/kg) e sob o efeito destes anestésicos, foram decapitados em guilhotina e o segmento torácico da coluna vertebral foi dissecado na região do cruzamento das bandas elásticas, entre T7 e T10, para posteriores análises histomorfométricas.

Os segmentos foram fixados em formol tamponado a $10 \%$, por 24 horas, à temperatura ambiente. Em seguida foi realizada a descalcificação em ácido tricloroacético $5 \%$, por aproximadamente dez dias. Após este tempo, os ossos foram lavados, clivados longitudinalmente, no plano mediano, tendo como base os processos espinhosos, desidratados em série crescente alcoólica, diafanizados e emblocados em parafina histológica, para serem seccionados em espessura de 7 micrômetros $(\mu \mathrm{m})$, utilizando-se de um micrótomo histológico (Olympus CUT 4055) e corados em Hematoxilina-Eosina (HE). Após a seleção das lâminas, as imagens foram obtidas por fotomicrografia, sugere-se incluir algumas imagens de lâminas selecionadas no aumento de 10x para mensuração do disco in- 
tervertebral. As imagens obtidas foram gravadas em formato JPEG e analisadas no programa Image-Pro-Plus versão 6.o (Media Cybernetics, Inc.).

Para a mensuração do disco intervertebral foi adotado, para fins de padronização, uma distância de $1.0 \mathrm{~mm}$, a partir do ligamento longitudinal anterior, para a mensuração da $\mathrm{H}_{1}$ (altura da porção anterior do disco); e a partir do ligamento longitudinal posterior para a mensuração do $\mathrm{H}_{3}$ (altura da porção posterior do disco); $\mathrm{H}_{2}$ e $\mathrm{H}_{4}$. Foram mensurados a partir do ponto médio da largura do disco intervertebral, para a verificação da altura disco e da altura e área do núcleo pulposo, respectivamente (figura 1).

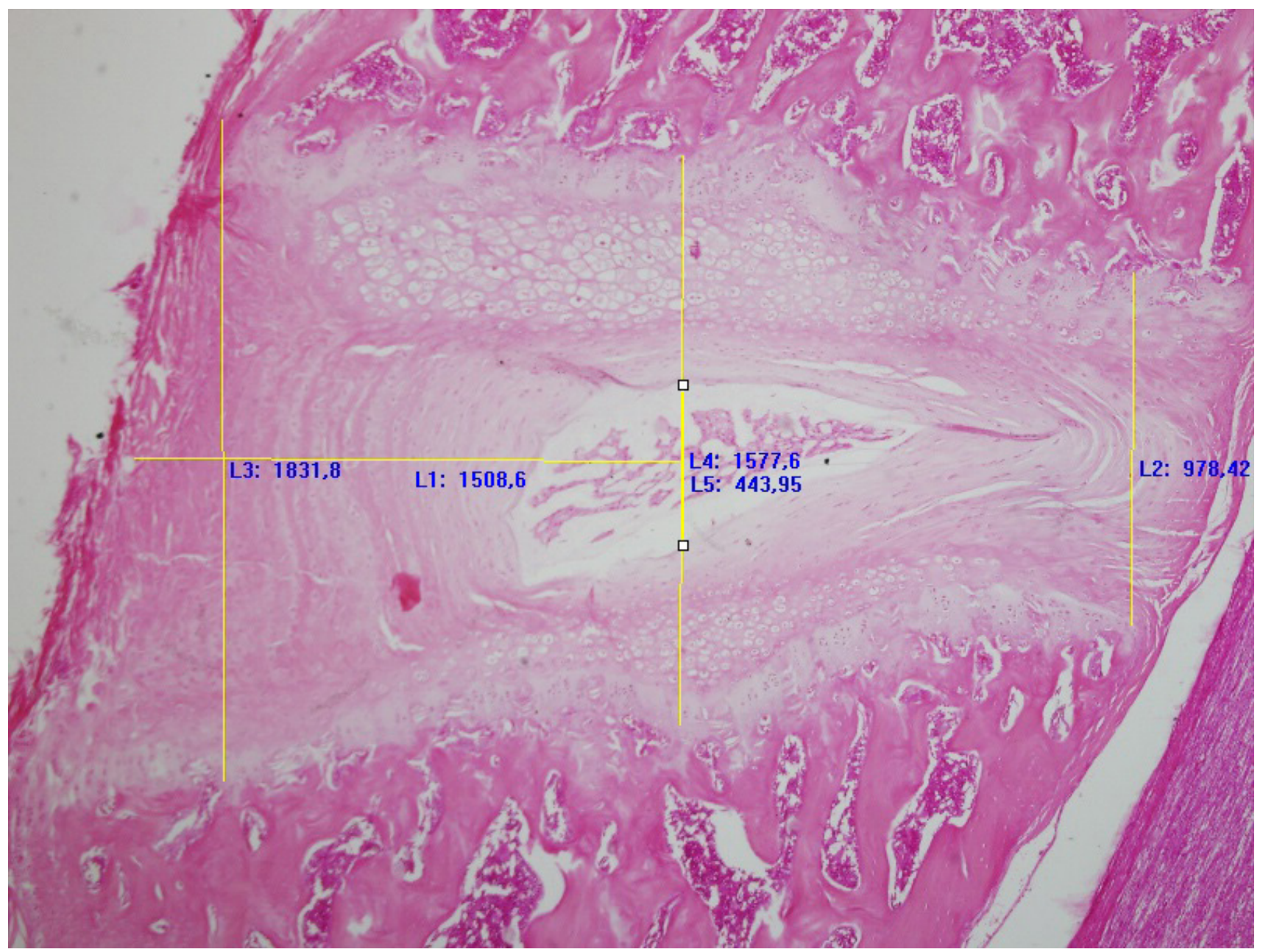

Figura 1 - fotomicrografia representativa das análises da altura do disco intervertebral, e núcleo pulposo, nas regiões anterior, média e posterior

Para a análise estatística foram utilizadas o teste de Shapiro-Wilk, para a verificação da normalidade dos dados e o Anova unidirecional, para a comparação entre os grupos, ambas com nível de significância de $5 \%$.

\section{RESULTADOS}

Os dados analisados mostram que não houve diferença significativa, na mensuração das alturas da porção anterior (A), porção medial (B) e porção posterior (C), demonstrados na figura 2 . 

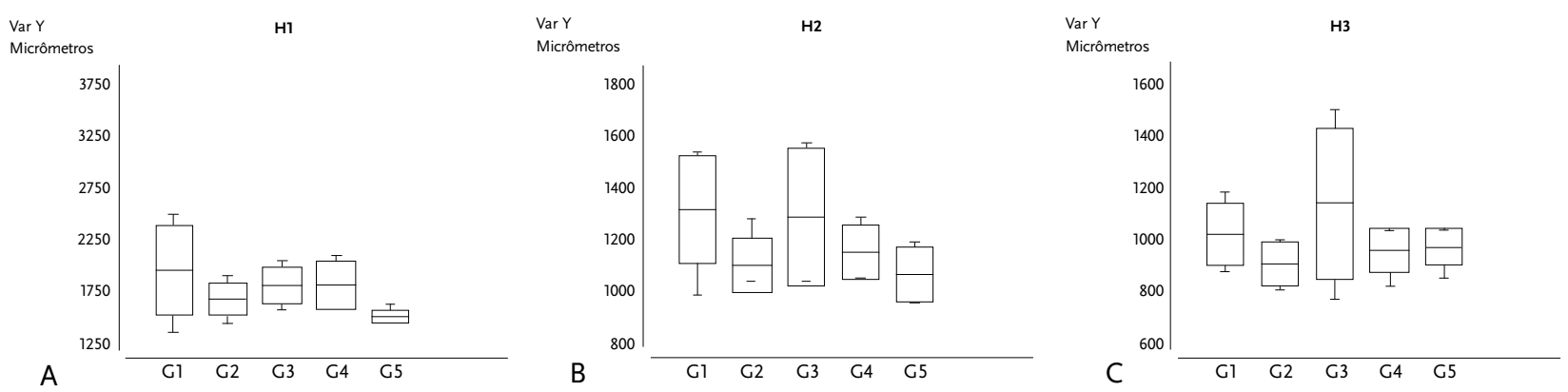

Figura 2 - Valores de média e desvio padrão da mensuração da altura do disco intervertebral, respectivamente nas regiões: (A) porção anterior; (B) porção média; (C) porção posterior.

Para a mensuração da altura do núcleo pulposo

ticas como demonstrado na figura 3. também não foram observadas diferenças estatís-

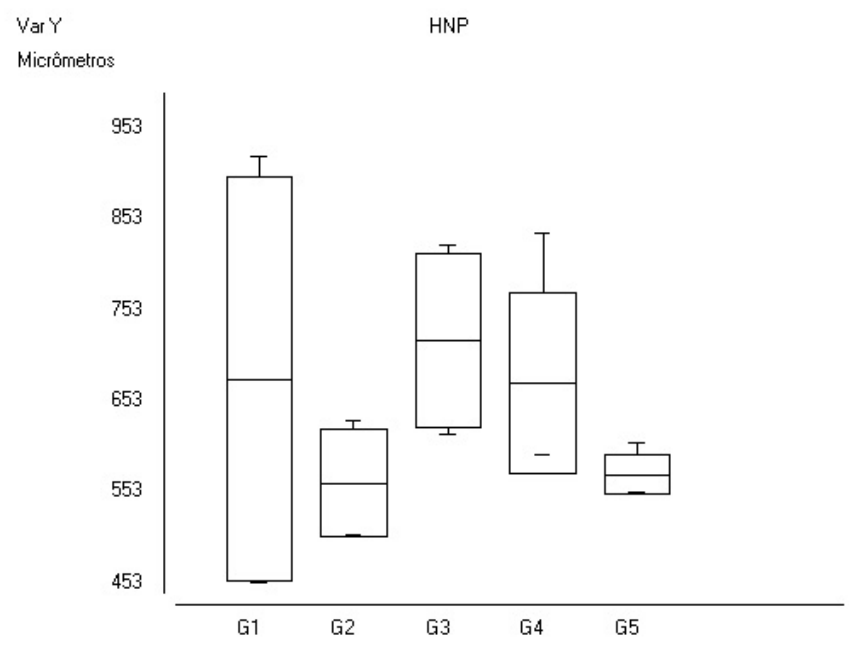

Figura 3 - Valores de média e desvio padrão da mensuração da altura do núcleo pulposo.

\section{DISCUSSÃO}

O modelo animal utilizado no experimento foi escolhido devido a seu fácil manuseio e obtenção dos animais para compor a amostra, sendo o mais utilizado em experimentos desta categoria por permitir a reprodução experimental de forma homogênea. ${ }^{(3,6)}$ Porém, os modelos de experimentação animal, que têm como finalidade a verificação do comportamento e dos mecanismos das forças de compressão sobre o disco intervertebral, são na sua maioria inconclusivos. Tal fato pode ser devido às relações de forças e tensões sobre os discos intervertebrais, que contribuem para a degeneração dos mesmos, ainda serem incertas, e a dificuldade de reprodução da complexa cascata de eventos que levam a degeneração discal. ${ }^{(3,15,16)}$ Outra dificuldade apontada é o fato dos ratos serem quadrúpedes, podendo assim apresentar respostas diferentes das observadas em humanos, contudo, salienta- 
se que durante o período de uso das roupas, os animais eram estimulados a continuarem se movimentando, inclusive assumindo, em alguns momentos, a postura bípede.

A vestimenta utilizada para simular uma sobrecarga sobre o animal foi projetada de forma a mimetizar as vestimentas utilizadas pelos programas de tratamento intensivo da fisioterapia, no tratamento de pacientes neurológicos, sendo o tempo de permanência também baseado nos protocolos utilizados por essas terapias intensivas. ${ }^{(14)}$ A única mudança foi a tensão sobre os elásticos, a qual foi proporcional ao peso do animal, e nos protocolos de tratamento em humanos a tensão é dada até o suficiente para realizar uma correção do posicionamento postural.(11,12) A graduação da carga de tensão dos elásticos, por meio da proporção do peso corporal, pode ter sido insuficiente para gerar alguma alteração discal.

As alterações morfológicas dos discos intervertebrais dependem primeiramente das mudanças microscópicas que ocorrem nas estruturas celulares que compõem o tecido conjuntivo dos discos intervertebrais, como demonstrado no estudo realizado por Guilak entre outros, ${ }^{(17)}$ no qual evidenciaram que quando o disco intervertebral é submetida a uma compressão, essa força provoca uma alteração na matriz extracelular desencadeando uma mudança na morfologia dos condrócitos, alterando assim, sua forma e volume celular, e também das fibras de colágeno. Quando retiradas as forças de compressão estas estruturas têm uma tendência de retornar à sua forma original. Tecidos com lesão, como a osteoartrite, apresentam uma alteração na capacidade de resposta dessas células perante as forças compressivas, acarretando em alterações permanentes na morfologia, metabolismo celular e função dos condrócitos.

Não só a compressão sobre o disco mais as forças aplicadas de forma errônea também prejudicam estruturalmente o disco como demonstrado no estudo de Colombier entre outros ${ }^{(1)}$ também demonstrou que tensões inadequadas sobre o disco intervertebral podem modificar o comportamento das células, levando-as a um mecanismo de apoptose, estimulado por estresse oxidativo. ${ }^{(18)}$ Essas alterações celulares são seguidas por uma alteração elástica e deformação viscosa do tecido, junto com perda de água no interior do disco intervertebral. (19) Assim, o tempo de permanência da vestimenta compressiva pode ter sido insuficiente para causar alterações morfométricas devido à perda de água, como, por exemplo, na altura do núcleo pulposo, o que explica a igualdade dos resultados em todos os grupos do experimento, sendo indicado em futuros estudos análises moleculares e também da estrutura celular, que poderiam indicar alterações iniciais da compressão discal.

Experimentos com ausência de cargas compressivas, com simulação de ausência de gravidade, como o realizado por jin entre outros ${ }^{(20)}$ evidenciam que há uma alteração de pressão hidrostática no interior dos discos intervertebrais, pela mudança na quantidade de proteoglicanos, induzindo apoptose das células do tecido articular, e posterior degeneração tecidual. Essas alterações de pressão hidrostática, quantidade de água intradiscal e capacidade celular de retenção de água, também foram observadas em discos com sinais de degeneração pela senescência. ${ }^{(10)}$ Roughley entre outros ${ }^{(21)}$ demonstraram que o processo degenerativo causa modificações estruturais, como o aumento das ligações cruzadas nas fibras de colágeno, diminuição das glicosaminoglicanose também alteração na capacidade de auto hidratação do disco intervertebral, demonstrando que a alteração na hidratação intradiscal e a capacidade de retenção de água pelas células, estão diretamente ligadas com a degeneração do disco intervertebral, o que também não foi analisado no presente estudo, sugerese que em estudos próximos sejam analisadas tais alterações. Ainda, visto que as mudanças bioquímicas e celulares dos animais utilizados em experimentos podem levar a uma variação na resposta celular às forças de compressão, é necessário um melhor entendimento do tempo necessário de aplicação destas forças para gerar alteração na morfologia do disco, o que poderá ser verificado em futuros estudos. 


\section{CONCLUSÃO}

Dentro do modelo e protocolo, de compressão do disco, propostos não houve alterações morfométricas do disco intervertebral torácico de ratos Wistar.

\section{REFERÊNCIAS}

1. Colombier P, Clovet J, Hamel O, Lescaudron L. The lumbar intervertebral disc: From embryonic development to degeneration. Jt Bone Spine. 2014;81(2):125-9.

2. Whatley BR, Wen X. Intervertebral disc (IVD): Structure, degeneration, repair and regeneration. Mater Sci Eng C. 2012;32(2):61-77.

3. Singh K, Masuda K, An HS. Animal models for human disc degeneration. Spine J. 2005;5(6):267S - 279S.

4. Moore RJ. The vertebral endplate: disc degeneration, disc regeneration. Eur Spine J. 2006;15(Suppl. 3):333-7.

5. Cavolina J, Evans G, Harris S, Zhang M, Westerlind K, Turner R. The effects of orbital spaceflight on bone histomorphometry and messenger ribonucleic acid levels for bone matrix proteins and skeletal signaling peptides in ovariectomized growing rats. Endocrinology. 1997;138(4):1567-76.

6. Zhou G, Yang F, Leung VVL, Cheung KMC. Molecular and cellular biology of the intervertebral disc and the use of animal models. Curr Orthop. 2008;22:267-73.

7. Roberts S, Evans H, Trivedi J, Menage OJ. Histology and pathology of the human intervertebral disc. J Bone Jt Surg Am. 2006;88(Suppl. 2):10-4.

8. Webb R, Brammah T, Lunt M, Urwin M, Allison T, Symmons D. Prevalence and predictors of intense, chronic, and disabling neck and back pain in the UK general population. Spine. 2003;28(11):1195-2O2.

9. Tulder MW Van, Koes BW, Bouter LM. A cost-ofillness study of back pain in The Netherlands. Pain. 1995;62(2):233-40.

10. latridis JC, Mente PL, Stokes IAF, Aronsson DD, Alini M. Compression-induced changes in intervertebral disc properties in a rat tail model. Spine. 1999;24(10):996-1002.

11. Therasuit. About TheraSuit. TheraSuit Method; 2014. [cited 2015] Available from: http://www. suittherapy.com/therasuit info.htm

12. $A D E L I . A D E L I$, rehabilitation and training center; 2014. [cited 2015] Available from: http:// www.adeli.gr

13. Frange CMP, Silva T de OT, Filgueiras S. Revisão sistemática do programa intensivo de fisioterapia utilizando a vestimenta com cordas elásticas. Rev Neurocienc. 2012;2O(4):517-26.

14. Borges MCD, Ribeiro LDFC, Brancalhão RMC, Bertolini GRF. Experimental model of suit therapy with traction bands in vertebral bone remodeling in wistar rats. J Nov Physiother. $2015 ; 5(4)$.

15. Lv F, Leung VYL, Huang S, Huang Y, Sun Y, Cheung KMC. In search of nucleus pulposusspecific molecular markers. Rheumatology. 2014;53(4):600-10.

16. Kepler CK, Ponnappan RK, Tannoury CA, Risbud M V, Anderson DG. The molecular basis of intervertebral disc degeneration. Spine J. 2013;13(3):318-30.

17. Guilak F, Jones WR, Ting-Beall H p, Lee GM. The deformation behavior and mechanical properties of chondrocytes in articular cartilage. Osteoarthr Cartil. 1999;7(1):59-70.

18. Li H, Liang CZ, Chen QX. Regulatory role of hypoxia inducible factor in the biological behavior of nucleus pulposus cells. Yonsei Med J. 2013;54(4):807-12.

19. Rodacki CL, Fowler NE, Rodacki AL, Birch K. Repeatability of measurement in determining stature in sitting and standing postures. Ergonomics. 2001;44(12):1076-85.

2O. Jin L, Feng G, Reames DL, Shimer AL, Shen $\mathrm{FH}, \mathrm{Li}$ X. The effects of simulated microgravity on intervertebral disc degeneration. Spine J. 2013;13(3):235-42.

21. Roughley PJ. Biology of intervertebral disc aging and degeneration involvement of the extracellular matrix. Spine. 2004;29(23):2691-9. 